\title{
Synthesis and Characterization of Cyclic Silenolates
}

\section{Michael Haas, Roland Fischer, Ana Torvisco and Harald Stüger}

Institute of Inorganic Chemistry, Graz University of Technology, Stremayrgasse 9/V, 8010 Graz, Austria

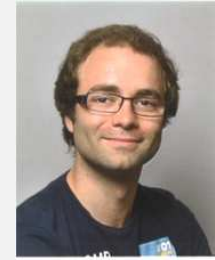

\section{Introduction}

Although silenes have been known for more than forty years, the synthesis and characterization of these compounds are still a challenging endeavor. Based on earlier work by Ottosson ${ }^{1}$ and Ohshita $^{2}$ the previously unknown cyclic silenolates 2a-c and 3a-b have been synthesized by the reaction of acylcyclohexasilanes with one or two equivalents of KOtBu. ${ }^{3,4}$ The nature of the anions (silenide or silenolate) and consequently the outcome of subsequent reaction steps largely depends on the substituent $\mathrm{R}$ at the carbonyl function. Detailed X-ray- and NMR-analysis of 2a-c and $\mathbf{3} \mathbf{a}-\mathbf{b}$ corroborate this deduction.

\section{Cyclic Silenolates}

Our new cyclic acylsilanes 1a-c reacted cleanly with 1.05 or 2.1 eq. of KOtBu to give the corresponding cyclic silenolates $2 \mathrm{a}-\mathrm{c}$ and the dianionic species $3 \mathrm{a}, \mathrm{b}$, respectively.

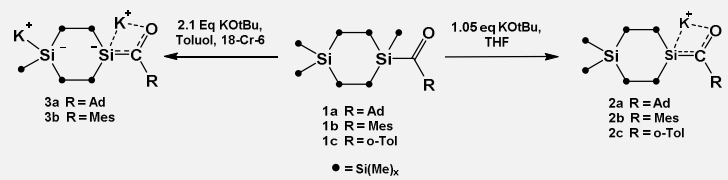

Upon heating to $50{ }^{\circ} \mathrm{C} \mathbf{2 b}$ undergoes a hitherto unknown 1,4-trimethylsilyl-migration and cleavage of the cyclohexasilane cycle to form the anion 4 which could be trapped with Mel to give an enantiomeric mixture of 5 from which the (S)-enantiomer could be crystallized.
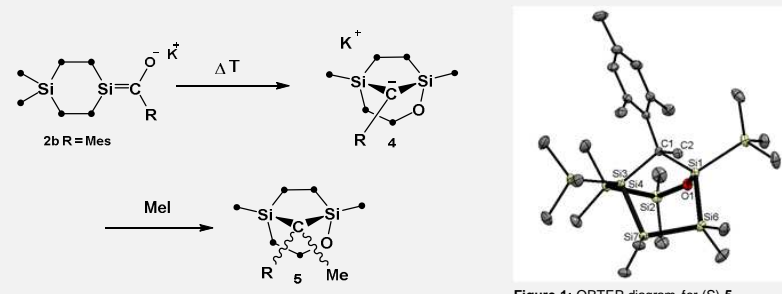

Figure 1: ORTEP diagram for (S) 5

Bis-silanolates could not be obtained because the silenolate intermediate 7 formed in the reaction of 1,4-bis-acylcyclohexasilane 6 with 1.05 to 2.1 eq. of KOtBu as the primary product immediately rearranges to the carbanionic species 8 in a related process:

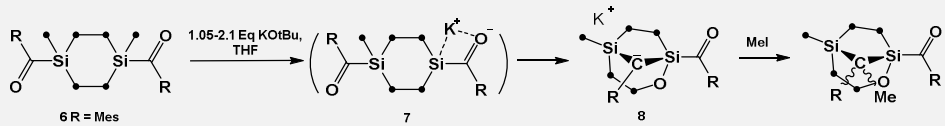

For $\mathbf{2} \mathbf{a}-\mathbf{c}$ and $\mathbf{3} \mathbf{a}, \mathbf{b}$ two resonance structures can be drawn: one with the negative charge residing predominately on the silicon atom (I), while in the other one (II) it is located on the oxygen atom.

located on the oxygen atom.

${ }^{29} \mathrm{Si} \mathrm{NMR}$ analysis suggests increasing contributions of structure II for the aromatic compounds $\mathbf{2 b}, \mathbf{c}$ and $\mathbf{3 b}$ as indicated by a marked low field shift of the $\mathrm{Si}_{1}$ signal relative to the adamantyl derivatives $\mathbf{2 a}$ and $\mathbf{3 a}$ (Table 1). Similar trends were reported earlier by Ohshita et al. ${ }^{2}$
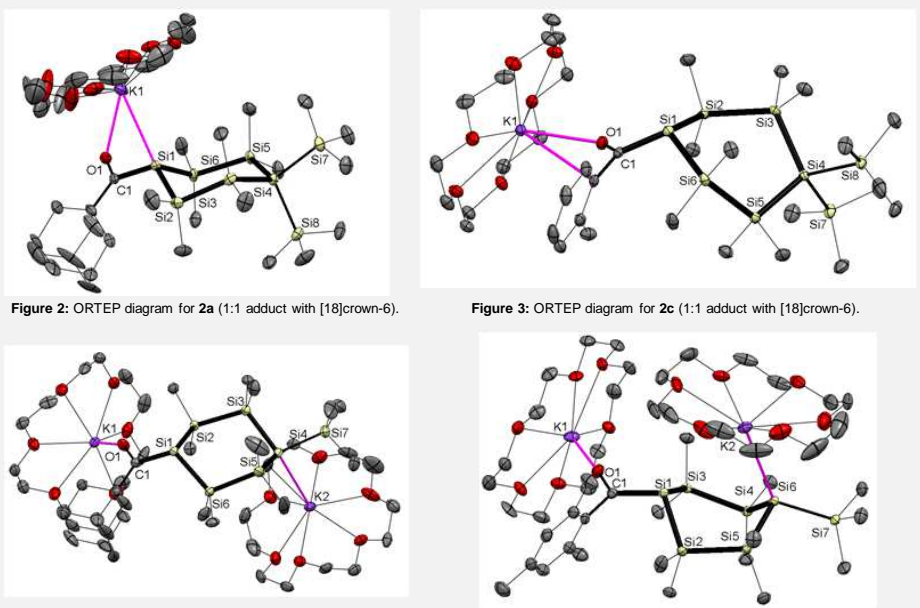

Figure 4: ORTEP diagram for $3 a$ (1:2 adduct with [18]crown-6).
Single crystal X-ray crystallography showed different coordination of the $\mathrm{K}^{+}$counterion to the $\mathrm{SiC}(\mathrm{R}) \mathrm{O}$ moiety in the solid state structure of $\mathbf{2 a}, \mathbf{c}$ and $\mathbf{3 a} \mathbf{a} \mathbf{b}$. While $\mathbf{2 a}$ and $3 \mathbf{a}, \mathbf{b}$ can be discribed as acyl silyl anions $\mathbf{2 c}$ exhibits increased silenolate character.

\begin{tabular}{|c|c|c|c|c|}
\hline & $2 a$ & $2 c$ & 3a & 3b \\
\hline 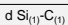 & 1.966 & 1.874 & 1.916 & 1.892 \\
\hline$d \mathrm{Si}_{(1,}-\mathrm{K}_{(1)}$ & 3.603 & 4.935 & 5.215 & 5.102 \\
\hline 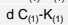 & 4.899 & 3.257 & 3.672 & 3.843 \\
\hline $\mathrm{dc}(1) \mathrm{O}_{(1)}$ & 1.244 & 1.260 & 1.254 & 1.254 \\
\hline $\mathrm{dK}_{\mathrm{K}(1)} \mathrm{O}_{(1)}$ & 2.743 & 2.701 & 2.579 & 2.614 \\
\hline$\sum a \mathrm{~S}_{(1)}$ & $316.7^{\circ}$ & $326.8^{\circ}$ & $314.4^{\circ}$ & $312.5^{\circ}$ \\
\hline$\Sigma a C_{1}$ & $359.9^{\circ}$ & $359.7^{\circ}$ & $359.7^{\circ}$ & $360^{\circ}$ \\
\hline
\end{tabular}

\section{Cyclic Silenes and Germenes}

If the silenolates $\mathbf{2 a - c}$ and $\mathbf{3 a , b}$ were reacted with chlorosilanes either silenes or new acylsilanes were formed depending on the nature of $\mathrm{R}$ attached to the carbonyl $\mathrm{C}$ : With aromatic R-groups the silenes $9 \mathrm{~b}, \mathrm{c}$ and $\mathbf{1 0 b}$ were obtained while aliphatic R-groups gave rise to the formation of the new acyl silanes $9 \mathrm{a}$ and $10 \mathrm{a}$.

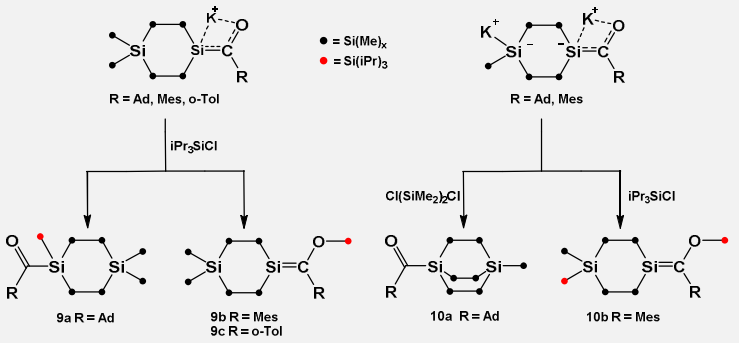

With this powerful synthetic strategy we also achieved the synthesis of the exocyclic germenolates 12a,b and the first exocyclic germene 13b:
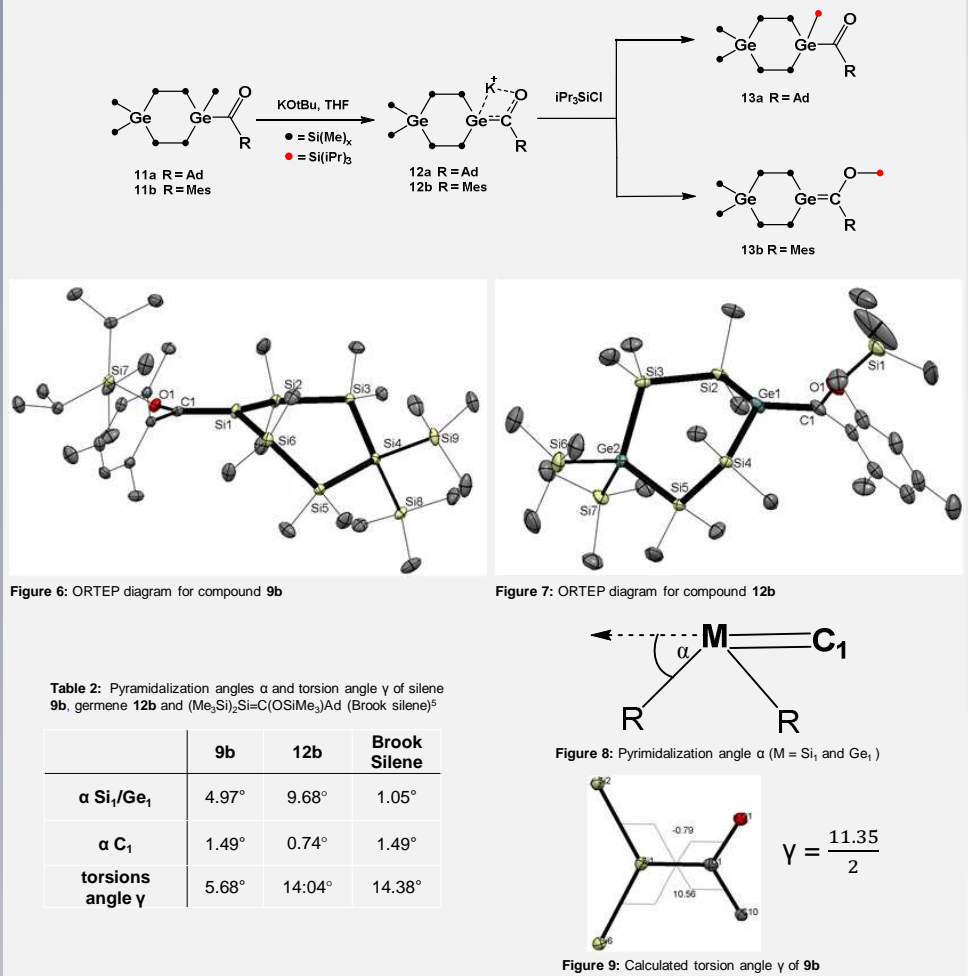

\section{Acknowledgement}

The Austrian Science Fund (FWF) and NAWI-Graz shall be gratefully acknowledged for financial support.

\section{References}

[1] T. Guliashvili, I. El-Sayed, A. Fischer, H. Ottosson, Angew. Chem., Int. Ed. 2003, 42, 1640. [2] J. Ohshita, S. Masaoka, Y. Masaoka, H. Hasebe, M. Ishikawa, Organomet. 1996, 15, 3136.
[3] H. Stueger, B. Hasken, M. Haas, M. Rausch, R. Fischer, A. Torvisco, Organometallics 2014, 33, 231.

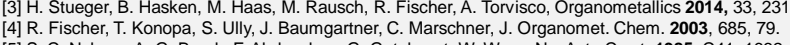
[5] S. C. Nyburg, A. G. Brook, F. Abdesaken, G. Gutekunst, W. Wong-Ng. Acta Cryst. 1985, C41, 1632. 